\title{
A crise hídrica no estado de São Paulo
}

\section{Julio Cerqueira Cesar Neto}

EP-USP

p. $479-484$

\section{revista}

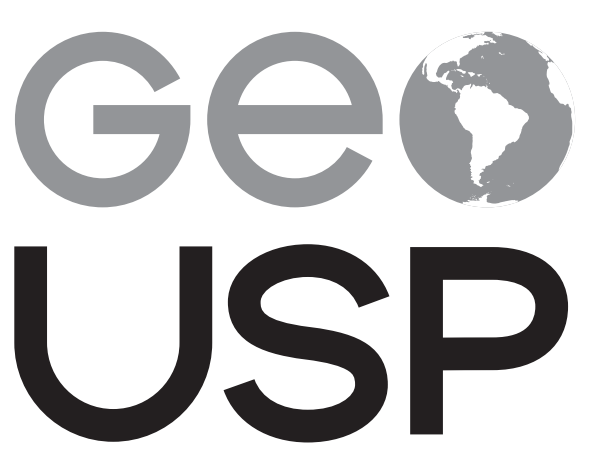

espaço e tempo

Volume $19 \cdot n^{\circ} 3(2015)$
Como citar este artigo:

NETO, J. C. C. A crise hídrica no estado de São Paulo. Geousp - Espaço e Tempo (Online), v. 19, n. 3, p. 479-484, mês. 2016. ISSN 2179-0892.

Disponível em: URL: http://www.revistas.usp.br/ geousp/article/view/101113. DOI: http://dx.doi. org/10.11606/issn.2179-0892.geousp.2015.101113.

\section{(c) (1) $(9)$}

Este artigo está licenciado sob a Creative Commons Attribution 4.0 License. 


\title{
A crise hídrica no estado de São Paulol*
}

\begin{abstract}
Resumo
A preocupação da Geousp com esse tema é extremamente oportuna, porque, em que pesem sua gravidade e importância, as informações disponíveis sobre ele são precárias e tendenciosas, impedindo a população de formar um juízo correto sobre todos os aspectos que o envolvem. Vários são esses aspectos, o que dificulta sua compreensão pelo público leigo. A crise é mais grave e importante na Região Metropolitana de São Paulo, configurando-se em escala diferente em algumas outras regiões e municípios.
\end{abstract}

Palavras-chave: Escassez. Disponibilidade. Racionamento. Gestão. Irresponsabilidade.

\section{The hydric crisis in Sao Paulo state}

\begin{abstract}
The concern of the Geousp about this theme is extremely timely because the information available about it, despite its gravity and importance, is biased, preventing the population to form a correct judgment about all aspects that are involved. There are many such aspects that promote the public understanding. The gravity and importance of the crisis in our State is located in the metropolitan region, its occurrence in some other regions and municipalities has another scale.
\end{abstract}

Keywords: Scarcity. Availability. Rationing. Management. Irresponsibility.

\section{A crise hídrica no estado de São Paulo}

Não está havendo uma crise hídrica no estado de São Paulo, mas apenas em algumas de suas bacias hidrográficas, assim como nos outros estados da região Sudeste, Minas, Rio de Janeiro e Espírito Santo.

Uma crise hídrica se caracteriza numa bacia quando ela sofre uma estiagem que reduz as precipitações pluviométricas além das necessárias para atender a suas demandas.

A preocupação da Geousp: Espaço e Tempo com esse tema é extremamente oportuna, porque as informações disponíveis sobre ele, em que pesem a sua gravidade e importância, são precárias e tendenciosas impedindo a população de formar um juízo correto sobre todos os aspectos que o envolvem. E são vários esses aspectos o que dificulta sua compreensão pelo público leigo.

$1{ }^{*} \bigcirc$ presente texto se baseia em observações e experiência própria. 
Observo de início, que a gravidade e importância da crise no nosso estado se localiza na Região Metropolitana de São Paulo (RMSP). No resto do estado, sua ocorrência em algumas regiões ou municípios se apresenta em outra escala. Por isso, foquei a abordagem preferencialmente nessa região.

\section{Aspectos que devem ser considerados (1) Conhecimento de nosso estado}

Nosso estado apresenta duas realidades que não podem ser ignoradas quando se pretende fazer qualquer análise ou avaliação: de um lado, a RMSP, com 22 milhões de habitantes e 8,5 mil km² de área, isto é, 2,6 milhões de habitantes por $\mathrm{km}^{2}$, com imensos problemas urbanos, sanitários, ambientais, socioeconômicos e político-institucionais e, de outro, o resto do estado, com 18 milhões de habitantes e 241,5 mil km²m, isto é, 75 habitantes por $\mathrm{km}^{2}$, que pode ser considerado civilizado.

\section{(2) A disponibilidade de água}

O estado é bem-dotado de águas tanto superficiais como subterrâneas; não apresenta áreas ou regiões áridas ou semiáridas. Assim sendo, as crises hídricas no estado só podem ocorrer em consequência de estiagens, que são fenômenos hidrometeorológicos naturais e fazem parte da variabilidade cíclica das precipitações que caem sobre determinada região.

\section{A disponibilidade de água na e para a RMSP}

Existe um mito de que essa região tem pouquíssima disponibilidade de água. Não é verdade. Ela não é diferente do resto do estado, inclusive, nas nascentes do Tietê junto à Serra do Mar, apresenta os maiores índices de precipitação do estado: 4.000 mm/ano. Certamente esse mito tem origem no fato - este verdadeiro - de que a RMSP não trata seus esgotos e transformou todos os seus canais, galerias, córregos e rios em canais de esgoto a céu aberto, e, nessas condições, imprestáveis para o abastecimento. Para os que não se deram conta, nossa importante região só começou a tratar seus esgotos, embora de forma ainda incipiente e insuficiente, em 2002, quando já tinha cerca de 18 milhões de habitantes. Mais recentemente, esse mito se tornou menos verdadeiro ainda, com o desenvolvimento das modernas tecnologias para a transformação dessas águas imprestáveis em águas de reuso, inclusive reuso potável.

Voltando à questão inicial, do mito de que a RMSP tem pouca água, lembro que o sistema Billings (reversão do rio Pinheiros e reservatório) propiciou a regularização da vazão de 100 m³ s da bacia do Alto Tietê à montante do Cebolão. Hoje, a demanda de água para a região, excluídas as perdas, seria da ordem de 50 a 60 m³/s. Após a construção do Cantareira, a reversão de $33 \mathrm{~m}^{3} / \mathrm{s}$ da bacia do Piracicaba aumentou a disponibilidade para $133 \mathrm{~m} / \mathrm{s}$.

Àqueles que ainda não estão dispostos a beber água de esgotos tratados, informo que existe disponibilidade de água de excelente qualidade e quantidade para abastecer a RMSP pelo resto da vida, com viabilidade técnica, ambiental e socioeconômica na bacia do Ribeira de Iguape, que atualmente lança no mar a vazão média de $520 \mathrm{~m}^{3} / \mathrm{s}$ suficientes para abastecer todas as cidades brasileiras. 


\section{(3) Os investimentos em produção de água para a RMSP}

Cantareira, concluído em meados da década de 1980, com produção de $33 \mathrm{~m}^{3} / \mathrm{s}$ quando a RMSP tinha cerca de 14 milhões de habitantes, foi o último grande investimento realizado. Depois, apenas mais $5,7 \mathrm{~m}^{3}$ /s foram acrescentados ao Alto Tietê em 2012, quando já abrigava mais de 21 milhões de habitantes, ou seja, quase nada.

Para manter o sistema metropolitano com "segurança hídrica", com capacidade suficiente para enfrentar estiagens como a que estamos enfrentando, teria sido necessário que o governo do estado (Companhia de Saneamento Básico do Estado de São Paulo - Sabesp) tivesse iniciado a construção de um novo Cantareira em 2001.

\section{(4) O sistema político e político-institucional}

A partir de 1990 ocorreu uma mudança radical no comportamento dos nossos governos (estadual e municipais) que passaram a se preocupar apenas com os processos eleitorais e largaram a administração das diversas políticas públicas de sua responsabilidade. Em consequência, os importantes e modernos sistemas político institucionais criados no estado cumprindo dispositivos da Constituição Federal de 1988 e Estadual de 1989, de um lado a Política Estadual de Recursos Hídricos (Lei n. 7.663/1991) e de outro a Política Estadual de Saneamento Ambiental (Lei n. 7.750/1992) foram praticamente ignoradas nesses 23 anos passados. $\bigcirc$ mesmo se deu com a Gestão Metropolitana que, para continuar a exercer as suas funções passou a depender de lei estadual de reorganização, e essa lei só veio em 2011, logo em seguida 2013 foi desativada. A Política de Recursos Hídricos e da Gestão Metropolitana por ação do próprio sistema político do governo, que teme dividir seu poder com os Comitês de Bacias Hidrográficas e com as prefeituras (o Comitê do Alto Tietê chegou a criar uma Agência, em 2002 - como seu braço executivo -, que foi desativada a partir de 2006).

A de Saneamento Ambiental, por ação decisiva da Sabesp (evidentemente com a compreensão do governo do estado), que pretendia e ainda pretende não abrir mão da sua completa liberdade de ação sem prestar contas a ninguém. A partir de 1990, a Sabesp substituiu a saúde pública pelo lucro e os usuários de seus serviços por seus acionistas, com a proteção do governo do estado, que, como acionista majoritário, passou a "ficar de olho" nos $51 \%$ da sua parte nos dividendos - $R \$ 250$ milhões por ano, ou $R$ \$ 1 bilhão em quatro anos de mandato.

\section{A crise hídrica atual se deve à falta dessas três políticas e à falta de inves- timento em novos mananciais \\ (5) O significado do abastecimento de água}

Há mais de 60 anos, é reconhecida mundialmente a enorme eficácia do sistema urbano de abastecimento de água para manutenção em níveis civilizados, os indicadores de saúde pública de qualquer comunidade. É também reconhecido no mundo todo que o investimento de cada real no abastecimento de água se traduz numa economia de $R$ \$ 4,00 em despesas com tratamento das doenças de "veiculação hídrica" que são contraídas devido a sua inexistência, como é o caso de surtos de diarreia, epidemias de febre tifoide, hepatites e até poliomielite. 
Esse fato foi comprovado aqui mesmo em São Paulo: no final da década de 1960, a RMSP tinha menos de 50\% da população servida com abastecimento de água e apresentava indicadores de saúde vergonhosos, entre eles, o mais importante, o de mortalidade infantil, tinha atingido 130 mortes por mil nascidos vivos. Para reforçar a decisão do governador Abreu Sodré de enfrentar a construção do sistema Cantareira (o maior sistema de produção de água individual do mundo), o eminente médico sanitarista Walter Leser elaborou em 1969 um excepcional estudo científico, no qual demonstrou que, a cada 10\% de ampliação no atendimento em abastecimento de água de uma população, corresponderia uma diminuição de 20 por mil no índice de mortalidade infantil. $\bigcirc$ sistema Cantareira foi construído e inaugurado no início dos anos 1980, quando a RMSP atingiu 100\% da população abastecida, ou seja, aumento de $50 \%$, e o índice de mortalidade infantil caiu para 30 por mil nascidos vivos, ou seja, diminuição de 100 por mil - exatamente conforme a previsão do professor Leser.

Nossa metrópole passou à condição de cidade civilizada, as doenças de veiculação hídrica foram erradicadas e o nível de saúde da população evoluiu. Passaram-se 30 anos, e agora a falta d'água pode nos fazer retroceder 50.

\section{(6) O racionamento (rodízio)}

O racionamento com esvaziamento e enchimento das redes de distribuição é indesejável num sistema de abastecimento porque pode comprometer a qualidade da água. $\bigcirc$ racionamento só é necessário quando a disponibilidade de água do sistema é menor do que a demanda, ou seja, o sistema é insuficiente. Um sistema só se torna insuficiente quando foi mal planejado e/ou mal construído e/ou mal operado, ou seja, não tem uma gestão competente, séria e responsável. Um sistema que possua esse tipo de gestão nunca fica insuficiente. É a gestão que um sistema de abastecimento de água tem que dispor para garantir o necessário atendimento permanente da população, sem interrupções.

\section{(7) A viabilidade do abastecimento de água}

Em geral, a execução de qualquer empreendimento precisa se mostrar viável. Um sistema de abastecimento de água é diferente: no caso de um sistema apresentar uma ou mais inviabilidades, seus responsáveis deverão superá-las para torná-lo viável. Nenhuma comunidade pode prescindir do abastecimento de água. Felizmente, no nosso estado, praticamente todos os sistemas apresentam viabilidade técnica, ambiental e socioeconômica, basta serem dotadas de gestão competente, séria e responsável.

\section{(8) A crise hídrica na RMSP}

Nosso governador, que assumiu o comando da crise desde o seu anúncio oficial, em janeiro de 2014, tem procurado (e conseguido) atribuí-la exclusivamente à maior estiagem dos últimos 84 anos, a caracterizando como calamidade pública totalmente imprevisível, escalando São Pedro como seu único responsável e eximindo seu governo de qualquer contribuição que pudesse vir a prejudicar seus objetivos eleitorais. Sabendo da fragilidade dessa argumentação, tem procurado também (e conseguido) minimizar sua gravidade, induzindo a população a acreditar que, com a chegada das chuvas, em outubro, os reservatórios voltarão a se encher e acabará a crise, argumento usado exaustivamente no ano passado e repetido este ano. 
Para tanto, tem se valido de expedientes que procura esconder da opinião pública, tais como:

- o veto ao plano da Sabesp para iniciar o racionamento (geral para toda a RMSP, apelidado de "rodízio") em janeiro de 2014;

- para evitar o racionamento a qualquer custo, determinou que fossem usadas todas as reservas disponíveis de água, inclusive as reservas técnicas, que passaram a ser conhecidas como "volumes mortos", aumentando os riscos de colapso do sistema como um todo;

- a insistente afirmação de que não existe nenhum racionamento, embora tenha autorizado em junho (após o esgotamento do volume útil do Cantareira) o racionamento "seletivo", qual seja, o que sacrifica apenas parte da população, especialmente da periferia e de baixa renda, pela redução de pressão e o fechamento de registros nas redes de distribuição.

Esses fatos foram descobertos pela imprensa sempre alguns meses após a sua ocorrência.

$\bigcirc$ governador ainda definiu algumas medidas estruturais emergenciais, em termos de disponibilizar vazões para ajudar a população, principalmente a parte que está sofrendo com o racionamento, a conviver com a crise a curto prazo: reversão de $5 \mathrm{~m}^{3} / \mathrm{s}$ do Jaguari para o Atibainha; 4 m³ s do Billings para o Alto Tietê e outras vazões menores. Entretanto todas estão atrasadas e nenhuma ficará pronta este ano.

Com relação às medidas estruturais em termos de novos mananciais de grande porte reclamados há 15 anos assim como a necessária reforma político institucional, todas absolutamente necessárias não só para sair dessa crise como também para impedir que crises como essa não aconteçam nunca mais não se observa nenhuma movimentação para atendê-las: nessas condições é muito provável que finda a estiagem a crise continue por falta de competência institucional e de capacidade de mananciais.

\section{A estiagem}

Não se trata de calamidade pública totalmente imprevisível, mas de fenômeno hidrometeorológico natural que faz parte da variabilidade cíclica das precipitações que caem sobre determinada região hoje previsiveis com relativa segurança.

A hidrologia moderna nos permite construir modelos sofisticados de descrição qualitativa e quantitativa de fenômenos aleatórios como os que ocorrem sob o rótulo simplificado de "ciclo hidrológico".

\section{A estiagem no Cantareira}

Para os professores da USP Pedro Luiz Côrtes, também coordenador da Rede Internacional de Estudos sobre Meio Ambiente e Sustentabilidade e da Unicamp, e Antônio Carlos Zuffo, a estiagem na região do Cantareira era previsível e deve durar ao menos mais 10 anos. Segundo eles, existem duas teorias diferentes sobre fenômenos climáticos longos e cíclicos que têm explicado a queda significativa do volume de água que entrou no Sistema Cantareira na última década: uma considera a temperatura do Oceano Pacífico e a outra os ciclos solares ambas chegam a essa mesma conclusão.

Um estudo feito pelo professor Côrtes projeta que o Cantareira só deve atingir um nível de segurança de 38\% de sua capacidade, sem incluir o volume morto, em oito anos. Ele sugere que esse prognóstico climático de médio e longo prazos seja incluído na nova forma de operação do sistema. 


\section{O sistema de abastecimento de água da RMSP}

A parte do sistema sob responsabilidade da Sabesp, hoje, conta com as águas do Cantareira (33 $\left.\mathrm{n}^{3} / \mathrm{s}\right)$; do Alto Tietê $\left(15 \mathrm{~m}^{3} / \mathrm{s}\right)$; do Guarapiranga $\left(14 \mathrm{~m}^{3} / \mathrm{s}\right)$ e de vários outros mananciais menores $\left(10 \mathrm{~m}^{3} / \mathrm{s}\right)$ perfazendo uma disponibilidade total de $72 \mathrm{~m}^{3} / \mathrm{s}$ e a demanda está na casa dos $82 \mathrm{~m}^{3} / \mathrm{s}$, configurando um déficit de $10 \mathrm{~m}^{3} / \mathrm{s}$ que corresponde ao consumo de cerca de 3 milhões de habitantes, ou seja, 14\% da população da RMSP.

Em 2001, a demanda se igualou à disponibilidade, ambas de 66,3 n³/s. Essa situação indicava à Sabesp de que já deveria ter iniciado a construção de um novo sistema de grande porte para atender ao crescimento da população; se passaram três governos e meio do estado nesse período, e esse reforço do sistema não foi ainda nem sequer anunciado, ou seja, trata-se de um atraso de 15 anos.

\section{Considerações finais}

Pelo exposto, fica evidente a irresponsabilidade dos três governos e meio do estado nestes últimos 15 anos:

- não fizeram os investimentos que tinham obrigação de fazer para manter o sistema de abastecimento de água em segurança, no que se refere especialmente à preservação da saúde de uma população que já ultrapassou os 20 milhões de habitantes;

- manteve a RMSP sem gestão metropolitana e impediu o desenvolvimento competente, sério e responsável das políticas estaduais de Recursos Hídricos e de Saneamento Ambiental;

- até hoje, não apresenta nenhum movimento no sentido de reverter essa situação, o que seria absolutamente necessário não só para sairmos dessa crise, como também para que pudéssemos acreditar que "uma dessas" nunca mais voltaria a acontecer.

A esta altura, já não é relevante discutir outros detalhes menos significativos. $\bigcirc$ fato é que a crise chegou para deteriorar uma situação que estava se deteriorando há 15 anos. 